\title{
Intra- and inter-rater reliability of thoracic spine mobility and posture assessments in subjects with thoracic spine pain
}

\author{
Jani Takatalo $0^{1,2^{*}}$, Jari Ylinen ${ }^{3}$, Tuomo Pienimäki ${ }^{4}$ and Arja Häkkinen ${ }^{1,3}$
}

\begin{abstract}
Background: The thoracic spine (TS) has been neglected in the study of the spine despite its essential role in the stability and posture of the entire spinal complex. Therefore, there is an inevitable need to investigate the reproducibility of different thoracic spinal posture measures used in subjects with TS pain.

Methods: Thirty-two subjects (16 females and 16 males, mean age 39 years) were evaluated by two physiotherapists on the same day to gauge inter-rater reliability and on two consecutive days to gauge intra-rater reliability. TS posture was assessed by observation, and thoracic spine mobility was measured by manual assessment of segmental flexion and extension mobility in a seated position. Additionally, posterior-to-anterior accessory mobility in a prone position was assessed manually. Moreover, cervicothoracic flexion in a seated position, thoracic posture, and thoracic flexion and extension mobility in a standing position were assessed with a tape measure, and flexion and extension mobility in a seated position and TS posture in seated and standing positions were measured with an inclinometer. The intraclass correlation coefficient (ICC), standard error of measurement (SEM), mean difference (MD), Bland-Altman (B\&A) plot features and coefficient of repeatability (CR) were calculated.
\end{abstract}

Results: The mean and standard deviation (SD) of the duration of TS pain was 22 (SD 45) months, with the intensity of pain being rated at 27 (SD 21) $\mathrm{mm}$ on a visual analogue scale (VAS). Intra-rater reliability was very strong (ICC $\geq 0.80$ ) for the evaluation of seated and standing upper TS posture, standing whole TS posture and seated lower TS posture with an inclinometer. Moreover, TS posture evaluation with a measuring tape, posture inspection in a seated position, and manual assessment of segmental extension were found to have very strong intra-rater reliability. Inter-rater reliability was very strong for inclinometer measurements of standing and seated upper TS posture as well as standing whole TS posture.

Conclusion: Intra-rater reliability was higher than inter-rater reliability in most of the evaluated measurements. Overall, posture measurements with an inclinometer were more reliable than mobility measurements with the same instrument. The manual assessments can be used reliably when same evaluator performs the examination.

(Continued on next page)

\footnotetext{
* Correspondence: jani.takatalo@fimnet.fi

${ }^{1}$ Faculty of Sport and Health Sciences, University of Jyvaskyla, Jyväskylä, Finland

${ }^{2}$ Medical Research Center Oulu, University of Oulu and Oulu University Hospital, Oulu, Finland

Full list of author information is available at the end of the article
}

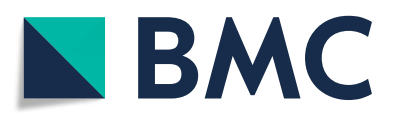

(c) The Author(s). 2020 Open Access This article is licensed under a Creative Commons Attribution 4.0 International License, which permits use, sharing, adaptation, distribution and reproduction in any medium or format, as long as you give appropriate credit to the original author(s) and the source, provide a link to the Creative Commons licence, and indicate if changes were made. The images or other third party material in this article are included in the article's Creative Commons licence, unless indicated otherwise in a credit line to the material. If material is not included in the article's Creative Commons licence and your intended use is not permitted by statutory regulation or exceeds the permitted use, you will need to obtain permission directly from the copyright holder. To view a copy of this licence, visit http://creativecommons.org/licenses/by/4.0/ The Creative Commons Public Domain Dedication waiver (http://creativecommons.org/publicdomain/zero/1.0/) applies to the data made available in this article, unless otherwise stated in a credit line to the data. 
(Continued from previous page)

Trial registration: Clinical Trials, NCT01884818. Registered 24 June 2013, https://clinicaltrials.gov/ct2/show/NCT01 884818 ?cond=thoracic + spine\&cntry $=$ Fl\&rank=1

Keywords: Thoracic, Spine, Pain, Reliability, Clinical examination, Manual therapy, Observation, Inclinometer, Tape measure, Palpation

\section{Introduction}

One-fifth of all people suffer from thoracic spine pain in their lifetime [1]. Niemeläinen et al. [2] found in their survey that $17 \%$ of males reported TS pain, with half of that subset reporting severe thoracic spine pain (visual analogue scale [VAS] rating $>80$ from 100 points on a numerical pain scale). One-quarter of these males experiencing thoracic spine pain had difficulties in daily activities. Female sex and younger age (children and adolescents) are also risk factors for thoracic spine pain. However, the prevalence is highly variable, ranging from 4 to $72 \%$ across different studies [1-3]. Patients with thoracic spine pain often undergo clinical evaluation to assess the need for therapy and measure its results [4]. Thus, it is necessary to study the reliability of the clinical methods for thoracic spine evaluation.

The thoracic spine is the stiffest part of the vertebral column due to the structural differences compared to the cervical and lumbar spine but also due to the thorax [4-7]. The thoracic spine contributes to cervical spine movements [8], flexion of the glenohumeral joint [9] and movement of the ribcage in respiration [10]. All innervated structures in the thoracic spine are capable of providing nociception. If active movements provoke pain, the movements are usually thoracic spine rotation or/ and extension [11]. Moreover, shoulder, upper limb and neck pain, and headaches, which are more commonly considered to originate from the cervical spine, may be referred from the thoracic spine instead [12-14]. In the half of all cases of thoracic spine pain seem to involve facet joints [15]. Unilateral thoracic spine pain from symptomatic thoracic spine facets is typically referred one or two segments cranially or caudally [16]. However, the two highest and three lowest thoracic facet joints often refer pain more widely and atypically than the others $[11,17]$.

Manual examination of the spine has been questioned as the target tissue of examination is controversial. Moreover, only a small number of studies have been published on manual palpation testing of the thoracic spine. In a recent study, Beynon et al [18] found interrater reliability of thoracic spine stiffness ranging between -0.11 and 0.53 with Kappa statistics. In the review on spinal motion palpation, only a few thoracic spine studies were referred and they found the intra-rater agreement of segmental thoracic spine flexion in sitting and posterior-to-anterior (PA) pressure assessment to be higher than $93 \%$,while in another study PA pressure assessment kappa values ranged from 0.43 to 0.55 and from 0.14 to 0.35 in intra-rater and inter-rater evaluation, respectively [19]. In more recent review on spinal motion palpation concluded, that there are no one superior manual method for physical assessment. Only one study on thoracic spine palpation was included which found kappa values of $0.34-0.77$ and $0.38-0.70$ for intrarater and inter-rater reliability, respectively [20]. Overall, it is more reliable to find the same painful thoracic spine segment than segment with movement dysfunction or restriction $[18,20]$. Although the movement dysfunction may be found, naming it similarly between raters or between evaluation sessions by the same rater is more challenging [19].

Several measurement devices have been used to measure the posture and mobility of the thoracic spine in the earlier studies. In the systematic review of thoracic spine posture found that most of the studies have been performed with asymptomatic subjects [21]. They also found that reliability may be excellent (Intra-Class Coefficiency, ICC, or Cronbach's alpha $>0.80$ ), however, validity has been less studied across the large variety of measurement devices. Tape measure has been used mainly in Schober measurement in the lumbar spine. In the lumbar spine flexion and extension intra-rater reliability (ICC) has been reported to be higher than 0.72 [22].

In clinical framework, examining spinal range of motion has been an important part of manual therapy practice [23, 24]. It has been reported that $98 \%$ of manual therapists evaluates passive movement of spinal segments as part of their clinical assessment [24]. The major deficiency of earlier studies is a small sample size or without sample size calculations, wide variations of palpation protocols and measurement devices, and mostly performed with asymptomatic subjects.

The thoracic spine, although neglected in the study of the vertebral column, is nonetheless an important part of the spine and can cause severe disability and pain if injured. Therefore, the reliable methods for clinical examination of thoracic spine are important. The aim of the current study is to investigate the intra- and interrater reliability of thoracic mobility and posture measurements taken manually and with measuring devices 
on subjects with cervicothoracic symptoms in order to increase knowledge of reliable measurements with which to investigate thoracic spine problems.

\section{Methods}

The subjects were referred for physical therapy by a physician due to thoracic spine pain or were recruited through advertisement in the local newspaper in the city of Oulu. The physician screened all the potential subjects for other medical conditions before their enrolment. The physical therapist of an outpatient clinic screened the volunteer participants for eligibility before the first visit. Each participant signed informed consent before the first assessment. The inclusion and exclusion criteria are listed in Table 1 . The present study was nested cohort study of the randomized controlled trial. The study was conducted according to the Declaration of Helsinki, and the Ethical Committee of Northern Ostrobothnia approved the protocol prior to the study.

The enrolled subjects completed a 24-h thoracic spine pain questionnaire (VAS, from $0=$ no pain to $100=$ worst pain imaginable), the Roland-Morris Disability Questionnaire (R-MDQ; 0-24 points) and the Thoracic Spine Pain and Disability (TSPD) questionnaire (sum of 13 items on a scale of $0-100 \mathrm{~mm}$ ) before each measurement day (Table 2). The questions on the TSPD were modified from the Neck and Shoulder Pain and Disability Index questionnaire [25] to apply to the thoracic spine region. The pain and disability questionnaires were used to obtain a general overview of the severity of the subjects' thoracic spine pain and their level of disability. Subjects were informed that they would receive feedback about the assessments after the final measurement. Moreover, in order to promote compliance among the subjects, they were rewarded with a 30 -min massage to be redeemed after the study.

\section{Measurement procedure}

Examinations were performed on two consecutive days by two physical therapists, who had been trained to perform all the measurements according to the same protocol. The physical therapists were blind to each other's results and to the results of the pain and disability questionnaires. On the first day, a physical therapist (JT) with 7 years of experience in manual therapy screened the subjects for eligibility and performed the first examination. On the following day, two similar sets of measurements were performed (by JT and JM) in a random order, with ten-minute intervals between assessments. The physical therapist performing the measurements on consecutive days (JT) was blind to the recordings of the initial measurement on the second examination. Each subject was examined at approximately the same time of day and the order of the examinations were similar on consecutive days. The other assessing physical therapist (JM) had 23 years of experience in manual physical therapy. Each mobility examination was performed maximum of two repetitions for each segment to reduce the mobilizing effect of assessment.

\section{Preparations for the assessment}

Before each assessment, the subjects were asked to sit, while the physical therapist palpated and marked the spinous process of the $\mathrm{C} 7$ vertebra with a pen. The spinous process of $\mathrm{C} 7$ was identified by cervical extension as spinous process of $\mathrm{C} 6$ appear to move anteriorly and $\mathrm{C} 7$ remains stationary during the movement [26]. Without extension C6 is found to be the most prominent spinous

Table 1 Inclusion and exclusion criteria of the study

\begin{tabular}{ll}
\hline Inclusion & Pain in thoracic spine area during baseline examination (VAS $>0)$ \\
\hline Exclusion & Daily thoracic spine pain during the last week(s) \\
& Pain produced in PA pressure test of the thoracic spine \\
& 18 to 55 years old \\
& Fibromyalgia \\
& Daily cervical or lumbar spine pain \\
& Inflammatory musculoskeletal diseases (i.e. rheumatoid arthritis, polymyalgia rheumatic) or any infection \\
& Spinal fracture or malignant disease \\
& Haemophilia or other blood disease \\
& Symptomatic angina pectoris \\
& Operation with thoracotomy \\
& Previous thoracic spine operation \\
& Cardiac pain \\
& Oesophageal pain
\end{tabular}

VAS Visual Analogue Scale; PA Posterior to anterior

a This study was part of the larger thoracic spine manipulation study and therefore upper cut-off age was 55 years of age 
Table 2 Thoracic Spine Pain and Disability questionnaire

\begin{tabular}{|c|c|}
\hline Question & Pain and disability scale from 0 to $100 \mathrm{~mm}$ \\
\hline How severe is your pain? & No pain - intolerable \\
\hline How severe is your pain at night? & No pain - intolerable \\
\hline Do you get relief from painkillers? & Complete relief - no relief \\
\hline How stiff is your thoracic spine? & No stiffness - intolerable stiffness \\
\hline Do you have discomfort when looking upwards? & None at all - intolerable \\
\hline Do you have discomfort when turning your head to the sides? & None at all - intolerable \\
\hline $\begin{array}{l}\text { Does your pain interfere with your ability to work with your hands } \\
\text { overhead? }\end{array}$ & No interference - completely unable to work with hands overhead \\
\hline Does your pain interfere with your ability to comb your hair? & No interference - completely unable to comb hair \\
\hline Does you pain interfere with your ability to put on your coat? & No interference - completely unable to put on coat \\
\hline How severe is your pain when lying down in bed? & No pain - intolerable \\
\hline $\begin{array}{l}\text { What is your overall handicap in your complete lifestyle because of your } \\
\text { pain? }\end{array}$ & Completely free to perform any task - totally handicapped \\
\hline To what extent does your pain interfere with your work? & No interference at all - totally incapable to work \\
\hline $\begin{array}{l}\text { To what extent have you had to modify your work in order to be able to } \\
\text { do your job? }\end{array}$ & $\begin{array}{l}\text { No adjustment to work - so much adjustment that you have had to } \\
\text { change your job }\end{array}$ \\
\hline
\end{tabular}

process in $48 \%$ of the subjects, but with extension test the spinous process of $\mathrm{C} 7$ can be found in $77-88 \%$ of subjects [27]. After the $\mathrm{C} 7$ spinous process was found and marked, the next mark caudally was drawn on the spine $15 \mathrm{~cm}$ from the marking of the spinous process of $\mathrm{C} 7$, theoretically representing the spinous process of $\mathrm{T} 5$ [28]. The T6 and T12 spinous processes were palpated by palpating caudally the spine and marked with the pen. All marks made on the spine were erased at the end of each assessment session to blind the physical therapists for their previous as well as each other's markings.

\section{Assessment of the thoracic spine posture}

The subjects were standing with the feet slightly apart (at the subject's typical standing width); the physical therapists evaluated the subject's thoracic spine posture from the side view and classified it as hypokyphosis, normal kyphosis or hyperkyphosis. The evaluation was a forced call methodology based on clinical experience of the posture of the thoracic spines, meaning the physical therapist had to classify the subjects' thoracic spine one of the categories before inclinometer measurements. The inclinometer (Saunders Digital Inclinometer, New York) was used to measure thoracic spine posture at the T1, T6 and T12 levels; for the first two measurements (T1 and T6), inclinometer was placed caudally so that the edge of the upper contact pillar of the inclinometer was in contact with markings, whereas in the third measurement (T12), the edge of the lower contact pillar of the inclinometer was cranial to the T12 marking. The same measurements were performed in a sitting position (Fig. 1); the subject was encouraged to sit in his or her natural position. The actual inclination of the thoracic spine was calculated based on these values for the upper (from T1 to T6), lower (from T6 to T12) and whole TS (from $\mathrm{T} 1$ to T12). These measurements of thoracic spine posture have been earlier described by Czapowski et al [29] in standing.

\section{Assessment of the thoracic spine mobility with inclinometer and tape measure}

Active thoracic spine flexion and extension were measured while the subject was sitting. The subject was asked to flex the spine as far as they could despite a possible increase in thoracic spine pain. The thoracic spine flexion was measured with both a tape measure (1) and an inclinometer (2). The upper thoracic spine (C7-T5) mobility was measured as suggested by Norlander et al. [28]; the difference between the marks on spinous processes of $\mathrm{C} 7$ and theoretical $\mathrm{T} 5(15 \mathrm{~cm}$ from the marking of C7) in neutral and maximum flexion was recorded. The thoracic spine Schober test was performed in a sitting position from the spinous process of $\mathrm{T} 1$ to that of T12. Measurements were performed in a neutral position and in active end-range flexion of the thoracic spine, and the difference between these measurements was recorded as the thoracic spine Schober flexion value. The extension of the thoracic spine was measured similarly by calculating the difference between neutral and active end-range thoracic spine extension tape measurements, and the value was recorded as the thoracic spine 


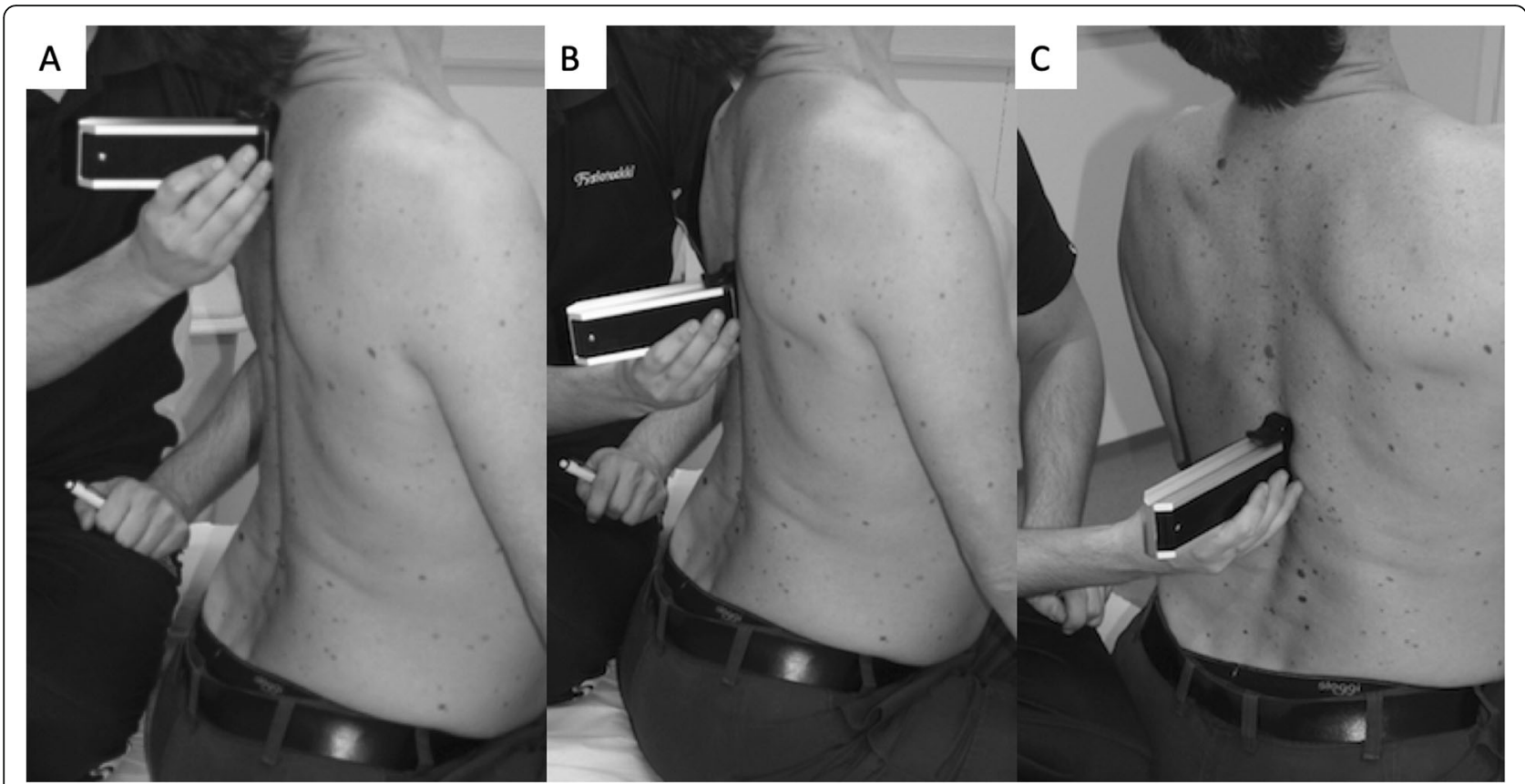

Fig. 1 The assessments of the thoracic spine extension with inclinometer in sitting. The assessments were performed in upper thoracic spine (a; Th1), mid-thoracic spine (b; Th6), and lower thoracic spine (c; Th12). Similar measurements were performed in maximum flexion of the thoracic spine. The thoracic spine posture was evaluated in same three locations in sitting and standing while subject maintained his/her typical posture

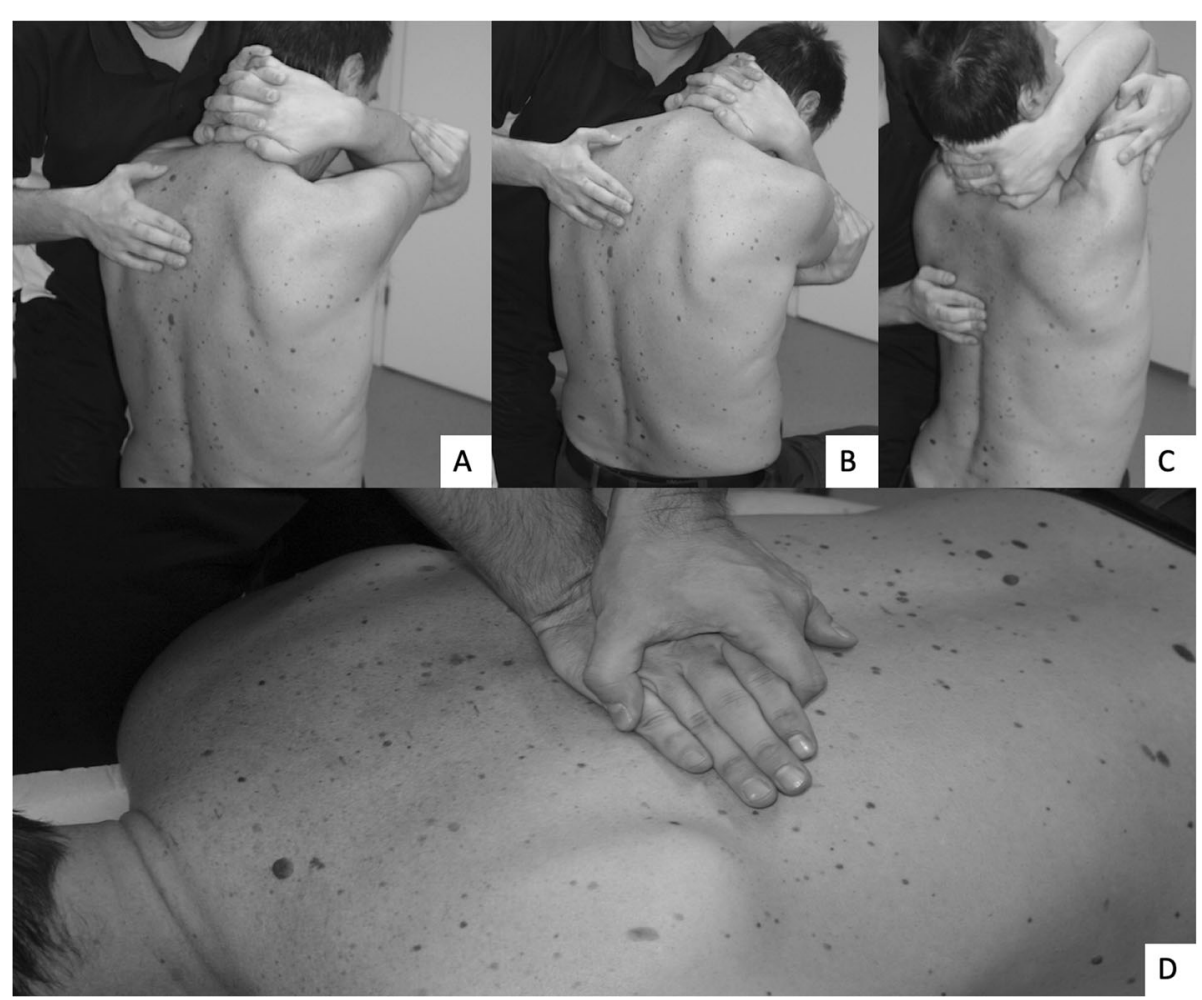

Fig. 2 Manual assessment of the thoracic spine mobility. Each thoracic spine movement segment of the thoracic spine was palpated in sitting (ac) and prone (d). In sitting, segmental evaluation started from the neutral position of the segment (a), followed by guided flexion (b) and extension (c) movement while physical therapist palpated the interspinous space to evaluate the mobility of the thoracic spine segment. In prone (d), posterior-anterior pressure was applied to feel the accessory movement of each thoracic spine segment 
Schober extension value [26]. The inclination of T1, T6 and T12 was measured in active end-range thoracic spine flexion and extension to determine the upper, lower and total thoracic flexion and extension. The contact pillars placements of the inclinometer were similar as for thoracic spine posture measurements. The differences between neutral and maximum flexion angles and between neutral and maximum extension angles were used as flexion and extension mobility values, respectively (Fig. 1). As we aimed to measure the maximum available active range of motion in the thoracic spine, we did not prohibit the lumbar movement as it is impossible to do maximum thoracic movement without moving the lumbar spine. Moreover, we were interested in whether the reliability would change if thoracic spine is measured in two halves, as thoracic spine is the longest part of the vertebral column and biomechanics of the upper thoracic spine is different compared to the lower part.

\section{Manual assessment of the thoracic spine mobility}

The segmental intervertebral motion was assessed in the sitting position as the subject was (semi) passively moved from a neutral posture into (1) flexion and (2) extension (Fig. 2) [26, 30]. Subjects were allowed to take part of the movement although the movement was mainly performed by physical therapist. The subject clasped both hands behind the neck and kept the elbows together in front. The physical therapist flexed and extended the thoracic spine through the subject's elbows with one hand while using the other to palpate the movement between spinal processes. The possible hypermobile segment was recorded as normal. The evaluation was a forced call methodology based on clinical experience of the manual assessment of the thoracic spine and comparing the adjacent movement segment to each other, meaning the physical therapist had to classify each segment whether normal of hypomobile i.e. stiff and evaluation was made in both directions (flexion and extension). The quality of motion of the thoracic spine segments at end-range, i.e. end-feel, was evaluated by applying posterior-anterior (PA) pressure to each spinous process (3) while the subject was prone on treatment table $[26,30,31]$, and the results were recorded as either mobile or hypomobile (Fig. 2). As in manual assessment of the thoracic spine flexion and extension, the evaluation was a forced call methodology based on clinical experience of the end-feel of the thoracic spine, meaning the physical therapist had to classify the subjects' thoracic spine either normal (normal "springiness") or stiff (no "springiness" or "hard end-feel").

\section{Statistics}

The number of subjects needed for the current study was based on the two evaluators, with statistical significance being defined as $p<0.05$, power being 0.20 , assuming that the intraclass correlation coefficient (ICC) was at least 0.50 with assumption that the reliability would be 0.80 . These assumptions showed the appropriate number of subjects to be at least 22 [32]. The differences in demographic variables between genders were analysed by independent Student's t-test and Fisher's exact test. Moreover, paired-samples Student's t-test was used compare the inclinometer values of thoracic spine posture between sitting and standing. The intra-rater and inter-rater reliability of the thoracic spine posture and mobility assessments was analysed using the ICCs (two-way mixed, average measures, consistency). Intraclass correlation was classified as very weak (0.01 to $0.19)$, weak $(0.20-0.39)$, moderate $(0.40-0.59)$, strong $(0.60-0.79)$ or very strong $(\geq 0.80)$ [33]. Moreover, the 95\% confidence intervals of the ICC were calculated, along with Cronbach's alpha. In order to evaluate the amplitude of differences, the standard error of measurement (SEM), the mean of differences and the coefficient of repeatability were calculated. The calculation of SEM was based on standard deviation (SD) and ICC (r); SD $\sqrt{(1}-r)$. Coefficient of repeatability (CR) was calculated by multiplying the SEM with 2.77 [34]. Bland-Altman plots were used to evaluate the $95 \%$ limits of agreement among measurements, and linear regression was performed to test the proportional bias of the BlandAltman plots. The data analyses were performed using SPSS software for Mac (version 24.0, SPSS Inc., Chicago, IL), however, SEM and CR were calculated manually.

\section{Results}

The mean age of the participants $(N=32)$ was 39 (standard deviation, SD 9.4) years, the duration of thoracic spine pain was 22 (SD 45) months, and the mean intensity of pain in previous $24 \mathrm{~h}$ (VAS) was $27 \mathrm{~mm}$ (SD 21). The subjects' mean TSPD score was $303 \mathrm{~mm}$ (SD 211) The mean R-MDQ score was 2.3 (SD 2.2) out of a maximum of 23 points. The mean body mass and height of the subjects were $73 \mathrm{~kg}$ (SD 15) and $167 \mathrm{~cm}$ (SD 29), respectively. Males had higher BMI and weighted more than females, but otherwise characteristically genders did not differ from each other. Additional details on the symptom characteristics and demographic data are shown in Table 3.

\section{Thoracic kyphosis angulation differences in sitting vs. standing}

In inclinometer-based posture measurement, there was no significant difference between the standing and seated posture of the upper thoracic spine, but lower and whole thoracic spine kyphosis were straighter in a seated position than in a standing position $\left(9^{\circ}\right.$ vs. $11^{\circ}$, 
Table 3 The mean and standard deviation (SD) or prevalence of the demographic variables of the study subjects

\begin{tabular}{|c|c|c|c|c|}
\hline & Females & Males & Gender difference & All \\
\hline & $N=16$ & $N=16$ & $p$-value (df) & $N=32$ \\
\hline Age, years (SD) & $39(10.6)$ & $39(8.4)$ & $0.956(30)^{*}$ & $39(9.4)$ \\
\hline Height, cm (SD) & $164(5.0)$ & $169(41.9)$ & $0.637(30)^{*}$ & $167(29.4)$ \\
\hline Weight, Kg (SD) & $63.2(9.6)$ & $82.8(12.4)$ & $<0.001(29)^{*}$ & $72.7(14.7)$ \\
\hline Body mass index, $\mathrm{Kg} / \mathrm{m}^{2}$ (SD) & $23.4(3.3)$ & $25.6(2.8)$ & $0.053(29)^{*}$ & $24.5(3.2)$ \\
\hline TS pain, months (SD) & $24.1(52.4)$ & $20.6(37.9)$ & $0.827(30)^{*}$ & $22.4(45.0)$ \\
\hline VAS, mm (SD) & $29.1(22.9)$ & $24.7(19.2)$ & $0.558(30)^{*}$ & $26.9(20.9)$ \\
\hline R-MDQ, points (SD) & $2.1(1.8)$ & $2.4(2.5)$ & $0.689(30)^{*}$ & $2.3(2.2)$ \\
\hline NSPD, points (SD) & $316(211)$ & $291(217)$ & $0.738(30)^{*}$ & $303(211)$ \\
\hline Smoking, \% (N) & $12.5(2)$ & $12.5(2)$ & $1.000(1)^{\S}$ & $12.5(4)$ \\
\hline Physician consultation, \% (N) & $43.8(7)$ & $56.3(9)$ & $0.724(1)^{\S}$ & $50.0(16)$ \\
\hline Pain medication for TSP, \% (N) & $18.8(3)$ & $6.3(1)$ & $0.600(1)^{\S}$ & $12.5(4)$ \\
\hline Earlier MT intervention, \% (N) & $87.5(14)$ & $93.8(15)$ & $1.000(1)^{\S}$ & $90.6(29)$ \\
\hline Systemic disease $\%$ (N) & $12.5(2)$ & $25.0(4)$ & $0.654(1)^{\S}$ & $18.8(6)$ \\
\hline
\end{tabular}

$d f$ Degree of freedom; TS Thoracic spine; VAS Visual analogue scale; R-MDQ Roland-Morris Disability Questionnaire (maximum points 24); NSPD Modified Neck and Shoulder Pain and Disability questionnaire (maximum score 1300, thirteen questions about pain and disability, each evaluated on VAS from 0 to 100 mm); MT Manual therapy

* Independent T-test was used for gender differences

$\S$ Fisher's exact test was used for gender differences

" At least one reported systemic disease

Table 4 The mean, SD and range of the thoracic spine posture and mobility measurements

\begin{tabular}{|c|c|c|c|c|c|c|}
\hline & \multicolumn{2}{|l|}{$\begin{array}{l}\text { Females } \\
N=16\end{array}$} & \multicolumn{2}{|l|}{$\begin{array}{l}\text { Males } \\
N=16\end{array}$} & \multicolumn{2}{|l|}{$\begin{array}{l}\text { All } \\
N=32\end{array}$} \\
\hline & Mean (SD) & Range & Mean (SD) & Range & Mean (SD) & Range \\
\hline \multicolumn{7}{|l|}{ Thoracic posture, standing $\left({ }^{\circ}\right)^{a}$} \\
\hline Upper (Th1-6) & $17.0(5.4) p=0.774, \mathrm{df} 15$ & $5-25$ & $22.9(4.0) p=0.193, \mathrm{df} 15$ & $16-31$ & $19.9(5.6) p=0.329, \mathrm{df} 31$ & $5-31$ \\
\hline Lower (Th6-12) & $9.4(4.6) p=0.022, \mathrm{df} 15$ & $0-16$ & $13.2(4.2) p=0.062, \mathrm{df} 15$ & $6-20$ & $11.3(4.8) p=0.008, \mathrm{df} 31$ & $0-20$ \\
\hline Upper and lower (Th1-12) & $27.0(7.2) p=0.114, \mathrm{df} 15$ & $12-40$ & $36.1(4.5) p=0.006, \mathrm{df} 15$ & $26-44$ & $31.5(7.5) p=0.001$, df 31 & $12-44$ \\
\hline \multicolumn{7}{|l|}{ Thoracic posture, sitting $\left({ }^{\circ}\right)^{a}$} \\
\hline Upper (Th1-6) & $17.3(5.0)$ & $5-23$ & $21.0(8.1)$ & $5-38$ & $19.1(6.9)$ & $5-38$ \\
\hline Lower $($ Th6-12) & $7.7(4.9)$ & $-3-15$ & $9.9(7.3)$ & $-3-22$ & $8.8(6.2)$ & $-3-22$ \\
\hline Upper and lower (Th1-12) & $24.9(6.0)$ & $10-32$ & $30.7(7.0)$ & $20-45$ & $27.8(7.1)$ & $10-45$ \\
\hline C7-Th5 flexion mobility (mm) & $27(5)$ & $18-40$ & $27(5)$ & $20-38$ & $27(5)$ & $18-40$ \\
\hline Schober (spine in flexion; mm) & $41(10)$ & $24-60$ & $45(11)$ & $27-65$ & $43(11)$ & $24-65$ \\
\hline Schober (spine in extension; $\mathrm{mm})^{c}$ & $22(11)$ & $2-45$ & $23(14)$ & $-7-45$ & $22(13)$ & $-7-45$ \\
\hline \multicolumn{7}{|l|}{ Thoracic flexion mobility, sitting $\left({ }^{\circ}\right)$} \\
\hline Upper (Th1-6) & $14.3(4.2)$ & $5-23$ & $13.5(6.5)$ & $3-25$ & $13.9(5.4)$ & $3-25$ \\
\hline Lower (Th6-12) & $12.4(4.8)$ & $4-21$ & $15.4(9.6)$ & $4-40$ & $13.9(7.6)$ & $4-40$ \\
\hline Upper and lower (Th1-12) & $26.1(5.0)$ & $15-32$ & $28.9(10.9)$ & $14-48$ & $27.5(8.5)$ & $14-48$ \\
\hline \multicolumn{7}{|l|}{ Thoracic extension mobility, sitting $\left(^{\circ}\right)$} \\
\hline Upper $\left(\right.$ Th1-6) ${ }^{d}$ & $12.1(7.4)$ & $-4-26$ & $12.1(12.1)$ & $-3-50$ & $12.1(9.8)$ & $-4-50$ \\
\hline Lower (Th6-12) ${ }^{d}$ & $5.2(6.1)$ & $-5-19$ & $5.1(6.4)$ & $-10-19$ & $5.2(6.1)$ & $-10-19$ \\
\hline Upper and lower (Th1-12) ${ }^{d}$ & $17.3(10.6)$ & $3-36$ & $17.2(16.6)$ & $-4-69$ & $17.2(13.7)$ & $-4-69$ \\
\hline
\end{tabular}

SD Standard deviation; Th Thoracic; $d f$ Degree of freedom

${ }^{a}$ The difference between sitting and standing measurements were evaluated with paired-samples $t$-test

${ }^{b}$ Negative values represent thoracic extension

c Negative values represent increased thoracic kyphosis (i.e. flexion) while trying to extend the thoracic spine

${ }^{d}$ Negative values represent inability to extend thoracic spine (i.e. thoracic spine remains in flexion while trying to extend it) 
$p=0.008$, for the lower thoracic spine and $28^{\circ}$ vs. $32^{\circ}$, $p=0.001$, for the whole thoracic spine, respectively). In the lower thoracic spine, a small but significant difference $\left(7.7^{\circ}\right.$ vs. $\left.9.4^{\circ}, p=0.022\right)$ was found in females but not in males. In the whole thoracic spine, a significant postural difference was found in males $\left(31^{\circ}\right.$ vs. $36^{\circ}, p=$ 0.006 ) but not in females. Further details are shown in Table 4.

\section{Inter-rater reliability}

The inspection of thoracic spine posture and the manual assessment of mobility had very low reliability in interrater evaluation. In contrast, inter-rater reliability was very strong for the inclinometer measurements of upper thoracic spine posture in sitting and standing positions (ICC 0.85 and 0.81 , respectively) and whole thoracic spine posture in a standing position (ICC 0.82). Other measurements did not reach to our target reliability of higher than 0.80 value. Inter-rater reliability was strong for the tape measurements in a neutral position and the thoracic spine Schober flexion value (ICC 0.74, both). Extension mobility measured with the inclinometer had strong reliability in the upper and whole thoracic spine
(ICC 0.61 and 0.62 , respectively), while the other mobility measurements were moderate at best. All the ICC values and measurement errors for inter-rater reliability are shown in Tables 5 and 6.

\section{Intra-rater reliability}

The inspection of the thoracic spine posture in standing and in sitting had strong or very strong reliability (ICC 0.78 and 0.87 , respectively) in intra-rater assessment. The segmental mobility assessment into extension had the highest values (ICC 0.80); however, other manual intra-rater assessments also had strong reliability values (ICC 0.69-0.73). The inclination measurements of the thoracic spine posture had strong or very strong intrarater reliability. Very strongly reliable part of the spine to measure with inclinometer was upper thoracic spine (0.86 and 0.84 in standing and sitting, respectively) whereas lower thoracic spine in standing and whole thoracic spine in sitting had only strong reliability $(0.70$ and 0.74 , respectively) (Table 5). Moreover, the neutral thoracic spine posture assessed with a measuring tape had very strong reliability $(0.86)$, while the thoracic spine Schober flexion and the C7-T5 flexion mobility had

Table 5 Inter- and intra-rater reliability (Intra-class correlation coefficients, ICC) with 95\% confidence interval (CI) and Cronbach's alpha of thoracic spine posture and mobility measurements

\begin{tabular}{|c|c|c|c|c|c|c|}
\hline \multirow[t]{2}{*}{ Variable } & \multicolumn{3}{|c|}{ Inter-rater $(n=32)$} & \multicolumn{3}{|c|}{ Intra-rater $(n=32)$} \\
\hline & ICC & Cl 95\% & Cronbach a & $\mathrm{ICC}$ & $\mathrm{Cl} 95 \%$ & Cronbach a \\
\hline Posture inspection while standing ${ }^{a}$ & 0.28 & $(-0.55-0.67)$ & 0.28 & 0.78 & $(0.56-0.89)$ & 0.78 \\
\hline Posture inspection while sitting ${ }^{a}$ & 0.23 & $(-0.58-0.62)$ & 0.23 & 0.87 & $(0.73-0.94)$ & 0.87 \\
\hline Segmental mobility into flexion ${ }^{b}$ & -0.07 & $(-1.20-0.48)$ & -0.07 & 0.79 & $(0.56-0.90)$ & 0.79 \\
\hline Segmental mobility into extension ${ }^{b}$ & -0.38 & $(-1.84-0.33)$ & -0.38 & 0.80 & $(0.59-0.90)$ & 0.80 \\
\hline Posterior to anterior pressure ${ }^{b}$ & -0.17 & $(-1.39-0.43)$ & -0.17 & 0.69 & $(0.37-0.85)$ & 0.69 \\
\hline Inclination of Th1-6 while standing $\left(^{\circ}\right)$ & 0.81 & $(0.60-0.91)$ & 0.82 & 0.86 & $(0.72-0.93)$ & 0.86 \\
\hline Inclination of Th6-12 while standing $\left(^{\circ}\right)$ & 0.69 & $(0.37-0.85)$ & 0.69 & 0.70 & $(0.39-0.85)$ & 0.72 \\
\hline Inclination of Th1-12 while standing $\left(^{\circ}\right)$ & 0.82 & $(0.64-0.91)$ & 0.82 & 0.83 & $(0.66-0.92)$ & 0.83 \\
\hline Inclination of Th1-6 while sitting $\left(^{\circ}\right)$ & 0.85 & $(0.67-0.93)$ & 0.86 & 0.84 & $(0.67-0.92)$ & 0.84 \\
\hline Inclination of Th6-12 while sitting $\left(^{\circ}\right)$ & 0.60 & $(0.18-0.80)$ & 0.60 & 0.80 & $(0.60-0.90)$ & 0.80 \\
\hline Inclination of Th1-12 while sitting $\left(^{\circ}\right)$ & 0.70 & $(0.37-0.85)$ & 0.69 & 0.74 & $(0.47-0.87)$ & 0.74 \\
\hline C7-Th5 flexion mobility (tape, mm) & 0.28 & $(-0.37-0.63)$ & 0.30 & 0.66 & $(0.30-0.83)$ & 0.65 \\
\hline Schober (spine in neutral, mm) & 0.74 & $(0.47-0.87)$ & 0.74 & 0.86 & $(0.72-0.93)$ & 0.86 \\
\hline Schober (spine in flexion, mm) & 0.74 & $(0.48-0.87)$ & 0.75 & 0.72 & $(0.43-0.86)$ & 0.73 \\
\hline Schober (spine in extensio, mm) & 0.29 & $(-0.48-0.66)$ & 0.28 & 0.30 & $(-0.42-0.66)$ & 0.30 \\
\hline Flexion mobility of Th1- 6 while sitting $\left(^{\circ}\right)$ & 0.19 & $(-0.67-0.60)$ & 0.19 & 0.64 & $(0.26-0.82)$ & 0.64 \\
\hline Flexion mobility of Th6-12 while sitting $\left(^{\circ}\right)$ & 0.52 & $(0.02-0.77)$ & 0.52 & 0.49 & $(-0.05-0.75)$ & 0.49 \\
\hline Flexion mobility of Th1-12 while sitting $\left(^{\circ}\right)$ & 0.48 & $(-0.06-0.75)$ & 0.48 & 0.67 & $(0.32-0.84)$ & 0.67 \\
\hline Extension mobility of Th1-6 while sitting $\left(^{\circ}\right)$ & 0.61 & $(0.20-0.81)$ & 0.61 & 0.35 & $(-0.33-0.68)$ & 0.35 \\
\hline Extension mobility of Th6-12 while sitting $\left(^{\circ}\right)$ & 0.58 & $(0.15-0.80)$ & 0.58 & 0.30 & $(-0.43-0.66)$ & 0.30 \\
\hline Extension mobility of Th1-12 while sitting $\left(^{\circ}\right)$ & 0.62 & $(0.22-0.81)$ & 0.62 & 0.46 & $(-0.10-0.74)$ & 0.46 \\
\hline
\end{tabular}

${ }^{a}$ Evaluated in three categories: decreased thoracic kyphosis (flat back), normal kyphosis or hyperkyphosis

b Sum of all thoracic spine motion segments recorded as hypomobile 
Table 6 Inter- and intra-rater reproducibility as standard error of measurement (SEM), mean of differences (MD), beta value of linear regression on Bland-Altman analyses (B) and coefficient of repeatability (CR) of thoracic spine posture and mobility measurements

\begin{tabular}{|c|c|c|c|c|c|c|c|c|}
\hline \multirow[t]{2}{*}{ Variable } & \multicolumn{4}{|c|}{ Inter-rater $(n=32)$} & \multicolumn{4}{|c|}{ Intra-rater $(n=32)$} \\
\hline & SEM & MD & $B^{C}$ & $C R$ & SEM & $\mathrm{MD}$ & $B^{c}$ & $C R$ \\
\hline Posture inspection while standing ${ }^{a}$ & 0.56 & -1.00 & -0.21 & 1.56 & 0.31 & 0.06 & -0.01 & 0.86 \\
\hline Posture inspection while sitting ${ }^{a}$ & 0.61 & -0.69 & -0.56 & 1.68 & 0.25 & -0.03 & -0.08 & 0.69 \\
\hline Segmental mobility into flexion ${ }^{b}$ & 2.62 & 0.88 & -0.69 & 7.27 & 1.16 & -0.53 & 0.34 & 3.22 \\
\hline Segmental mobility into extension ${ }^{\text {b }}$ & 3.26 & 1.91 & -0.13 & 9.03 & 1.24 & -0.50 & -0.02 & 3.44 \\
\hline Posterior to anterior pressure ${ }^{b}$ & 1.89 & 1.44 & -0.58 & 5.23 & 1.15 & -0.22 & 0.28 & 3.20 \\
\hline Inclination of Th1-6 while standing $\left(^{\circ}\right)$ & 2.43 & -2.0 & -0.26 & 6.73 & 2.10 & -0.81 & -0.15 & 5.80 \\
\hline Inclination of Th6-12 while standing $\left(^{\circ}\right)$ & 2.67 & 0.47 & -0.28 & 7.40 & 2.60 & 1.84 & -0.29 & 7.20 \\
\hline Inclination of Th1-12 while standing $\left(^{\circ}\right)$ & 3.18 & -1.34 & -0.25 & 8.81 & 3.09 & 1.34 & -0.10 & 8.57 \\
\hline Inclination of Th1-6 while sitting $\left(^{\circ}\right)$ & 2.66 & -2.16 & -0.15 & 7.37 & 2.76 & -0.94 & 0.02 & 7.65 \\
\hline Inclination of Th6-12 while sitting $\left(^{\circ}\right)$ & 3.92 & 1.28 & -0.19 & 10.86 & 2.77 & -0.97 & -0.11 & 7.68 \\
\hline Inclination of Th1-12 while sitting $\left(^{\circ}\right)$ & 3.87 & -0.53 & -0.17 & 10.72 & 3.62 & -1.34 & -0.18 & 10.03 \\
\hline C7-Th5 flexion mobility (tape, mm) & 4.17 & 3.59 & -0.75 & 11.59 & 2.87 & 0.72 & -0.15 & 7.95 \\
\hline Schober (spine in neutral, mm) & 16.08 & -4.47 & 0.08 & 44.55 & 11.80 & 2.47 & 0.12 & 32.69 \\
\hline Schober (spine in flexion, mm) & 5.47 & 2.41 & -0.20 & 15.15 & 5.67 & 2.22 & 0.26 & 15.71 \\
\hline Schober (spine in extensio, mm) & 10.53 & -4.75 & 0.21 & 29.17 & 10.88 & 0.13 & -0.03 & 30.13 \\
\hline Flexion mobility of Th1-6 while sitting $\left(^{\circ}\right)$ & 4.86 & 1.69 & 0.88 & 13.46 & 3.24 & 1.06 & 0.17 & 8.97 \\
\hline Flexion mobility of Th6-12 while sitting $\left(^{\circ}\right)$ & 5.27 & 4.22 & 0.94 & 14.59 & 5.43 & 1.91 & 0.62 & 15.03 \\
\hline Flexion mobility of Th1-12 while sitting $\left(^{\circ}\right)$ & 6.13 & -2.88 & 0.84 & 16.98 & 4.88 & 2.41 & 0.33 & 13.53 \\
\hline Extension mobility of Th1-6 while sitting $\left(^{\circ}\right)$ & 6.12 & 0.59 & 0.04 & 16.95 & 7.90 & -1.47 & 0.46 & 20.89 \\
\hline Extension mobility of Th6-12 while sitting $\left(^{\circ}\right)$ & 3.95 & 5.97 & 0.29 & 10.95 & 5.10 & -1.38 & -0.15 & 14.14 \\
\hline Extension mobility of Th1-12 while sitting $\left(^{\circ}\right)$ & 8.45 & 5.16 & 0.17 & 23.39 & 10.07 & -1.38 & 0.42 & 27.89 \\
\hline
\end{tabular}

${ }^{a}$ Evaluated in three categories: decreased thoracic kyphosis (flat back), normal kyphosis or hyperkyphosis

b Sum of all thoracic spine motion segments recorded as hypomobile

c The Bland Altman plots for each item are presented in the additional electronic files of this study; none of the linear regression for proportional bias were statistically significant

strong intra-rater reliability (ICC 0.72 and 0.66 , respectively). The maximum thoracic spine extension and flexion measured with the inclinometer had very weak to moderate and weak to strong reliability, respectively, on an intra-rater analyses. All the ICC values are presented for intra-rater reliability in Table 5, and the measurement errors are presented in Table 6. BlandAltman plots and 95\% limits of agreements are shown in additional electronic file. No proportional biases were detected when linear regression was performed for Bland-Altman plots.

\section{Discussion}

In the current study, the intra-rater reliability of thoracic spine posture inspection and manual assessments had at least strong reliability in the subjects with thoracic spine pain. Posture measurements with an inclinometer and Schober flexion with a tape had at least strong interand intra-rater reliability.

To the best of our knowledge, this study was the first to evaluate the reliability on wide range of posture and mobility measurements used in daily clinical practice for subjects with thoracic spine pain in a clinical setting. The major weakness of the pre-existing studies is the insufficient statistical analysis, as most of these studies reported only correlation coefficients or ICCs, and none reported the limits of agreement or other measurement error values. $\mathrm{Ng}$ et al. [35] reported the coefficient of variation to somewhat explain the dispersion around the mean of ICC, and Tousignant et al. [36] reported 95\% confidence intervals of ICC. Both of these studies reported at least moderate intra-rater reliability of the measurements of cervical and lumbar spine mobility with an inclinometer, but both were performed with asymptomatic subjects. More recently, one systematic review evaluated the reliability and validity of the thoracic and lumbar spine posture measurement reliability and reported that digital and manual inclinometer can be reliable method to evaluate spinal posture [21] similarly as we did. However, they did not report inclinometers to be the best evaluation method as the validity of these measure devices has not been studied thoroughly. 
One study has been published on same digital inclinometer that we used in the current study with very strong reliability (Cronbach's alpha 0.82-0.86), but the study was performed with asymptomatic subjects [29].

\section{Assessment of the thoracic spine posture}

An earlier study of 88 healthy subjects by Griegel-Morris et al. [37] found the intra- and inter-rater reliability of thoracic spine posture inspection to be 0.83 and 0.61 , respectively. Moreover, in another study, the inter-rater reliability of the observed thoracic spine kyphosis was found to be between 0.58 and 0.90 in subjects with cervical spine pain [38]. In our study, the inter-rater reliability was strong $(\mathrm{ICC}=0.78)$ in a standing position and very strong $(\mathrm{ICC}=0.87)$ in a sitting position in subjects with thoracic spine pain. Based on our result, we would recommend to be cautious when comparing posture evaluation between therapists as the inter-rater reliability was weak in sitting and standing positions (ICC $=0.23$ and 0.28 , respectively). In contrast to the earlier studies by Griegel-Morris et al [37] and Cleland et al [38], we did not find good inter-rater reliability in posture inspection, however, in line with the Griegel-Morris et al [37], the intra-rater reliability was higher than inter-rater reliability and reliability is acceptable for clinical use. Moreover, we found that reliability is even higher in sitting than standing, as earlier studies have only evaluated the posture inspection on standing $[37,38]$.

\section{Manual assessment of the thoracic spine mobility}

The manual evaluation of thoracic spine mobility has been criticized due to its low reliability, especially between observers [19, 38-41]. However, several studies have found the intra-rater reliability of thoracic spine mobility assessed manually to be at least moderate in symptomatic and asymptomatic subjects [19, 42-44]. However, the skill of finding the desired spinal segment and identifying it similarly between observers seems to be difficult and unreliable [45]; there seems to be a great difference between observers [40], and none of the palpation methods seem to be superior to evaluating thoracic spine mobility manually [24]. Heiderscheitet et al [46] reposted in the asymptomatic subjects the intrarater reliability of PA pressure of the thoracic spine has strong reliability (kappa $=0.61-0.75$ ), whereas in interrater reliability kappa value was lower (0.59). Our results are in line with Heiderscheitet et al [46], as inter-rater reliability in our study was very weak for PA pressure, whereas intra-rater reliability was strong. Walker et al [47] reported segmental mobility test of the thoracic spine in sitting to have weak inter-rater reliability (kappa $=0.36)$, which is in line with our results. However, we found intra-rater reliability to be strong or even very strong. The challenge in measurement is the accuracy of the palpation of thoracic spine segments, which has been reported to be poor in earlier studies [19]. This inaccuracy may also explain the low reliability of many inter-rater measurements, as in our study.

Earlier studies have stated that the finding of hypomobility or dysfunction in the symptomatic area of the spine seems to be more relevant than numbering the segment similarly between observers $[23,42]$. Therefore, the symptoms on the hypomobile area of the spine are clinically relevant when thoracic spine manipulation is the treatment of choice, as manipulation may increase thoracic spine mobility [48-51]. Therefore, manual assessment is important as part of the subject examination, and it can be quite reliable, especially when the same physical therapist performs the examination.

\section{Assessment of the thoracic spine posture and mobility with inclinometer and tape measure}

In the current study, the reliability of the posture measurements with an inclinometer were strong or very strong in both inter-rater and intra-rater evaluations. As palpation or subjective observation is only minimally involved in inclinometer measurement, it is understandable that this method of postural assessment would be more reliable. However, as in other measurements, the intra-rater reliability was better than inter-rater reliability. Czaprowski et al [29] have earlier reported that thoracic spine kyphosis can be measured with high reliability (Cronbach $\alpha>0.8$ ) in standing among asymptomatic subjects with as little as 3 degrees of measurement error. We found similar measurement error in our symptomatic subjects. Several other methods of measurements for the thoracic spine posture have been used and recently, their reliability and validity has been reported in the review. Most of the included measurement devices had very strong reliability and only a few were studied on their validity [21].

In an earlier study [22], the reliability of lumbar flexion and extension mobility measured with the modified Schober test was strong (ICC 0.72 and 0.76, respectively). In the current study, posture measured with a tape had strong reliability for inter-rater and very strong reliability for intra-rater measurements. However, Schober extension was not reliable in intra-rater or interrater measurements. One possible reason is the low degree of thoracic spine extension, which may make it challenging to obtain similar results in different measurements. Thus, we did not find good reliability of thoracic extension mobility measurements using a tape measure. We did not find any studies investigating the flexion or extension of the thoracic spine with tape measurement.

There are several studies investigating the reliability of cervical $[36,52]$ and lumbar spine $[35,53,54]$ mobility 
measurement devices among asymptomatic adults. Williams et al [22] reported lumbar spine flexion and extension mobility inter-rater reliability with double inclinometer (ICC 0.60 and 0.48 , respectively) and found that measuring flexion is more reliable than extension. In the current study, the thoracic spine extension mobility was most reliably measured using an inclinometer (whole and upper thoracic spine) between two therapists, while flexion mobility (whole and upper thoracic spine) was most reliable between consecutive days by the same therapist. Moreover, the reliability of the lower thoracic spine extension using an inclinometer was weak, perhaps due to the activation of spinal extensors, which could have made it difficult to place the inclinometer in firm contact with the spinous process because the contact pillar of the inclinometer was wider than the spinous process. We did not find any earlier reliability studies on thoracic spine mobility using a digital inclinometer. However, a few studies have been done for spinal mouse with at least strong inter- and intra-rater reliability (ICC $0.67-0.95$ and ICC $0.67-0.88$, respectively) $[55,56]$.

The range of normal kyphosis of the thoracic spine is 20 to 50 degrees [21]. In the current study, the mean thoracic kyphosis was within normal limits; however, there were also female subjects with hypokyphosis. In the present study, two thirds of the thoracic spine kyphosis was found in upper thoracic spine which is in line with earlier study by Czaprowski et al [29], however, they reported even higher proportion of thoracic spine kyphosis originating from upper thoracic spine. In asymptomatic males, extension has been reported to be more than 10 degrees, and one-third of the extension occurs in the upper thoracic spine [9]. We found the total extension of the thoracic spine to be $17^{\circ}$ in a sitting position. Contrary to Edmonston et al. [9], our subjects had two-thirds of the thoracic spine extension arising from the upper thoracic spine, while one-third was from the lower thoracic spine. One of the influencing factors may be the sitting posture of the subjects during measurements in the present study. Moreover, Edmonston et al [9] measured the range of motion into extension while flexing the upper limb. In the two studies in which the spinal mouse was used, total amount of thoracic spine flexion were 17 and 25 degrees in asymptomatic young elite cross-country skiers [57] and asymptomatic middle-aged subjects [56], respectively. In the present study, the mean age of the subjects was much closer to middle-aged than under 20-year-old and, therefore, it is more likely that our subjects should have similarities in the thoracic flexion mobility with subjects in the study of Mannion et al [56]. However, our subjects had extension of the thoracic spine similar to the young elite cross-country skiers (17 degrees) [57] as in the elder study population in the study by Mannion et al [56] the mean extension was reported to be only a few degrees.

\section{Strengths and limitations of the study}

The strength of this study is its ease of accessibility and inexpensive measurement devices, the reliability of which was measured in symptomatic subjects. The reliability on consecutive days was measured; however, week-to-week reliability was not studied, which is a limitation of the present study, as physical therapy sessions are often scheduled once a week. The second limitation of the study is that two physical therapists did the assessments only 10-min apart from each other and therefore some changes in mobility of the thoracic spine may have occurred. Thirdly, one physical therapist (JT) did the assessments on consecutive days and, therefore, there might have been a possibility to remember the initial recordings. However, this was not the case as physical therapist was requested to write down the previous results prior the second assessment and he was not able to do that. One of the strengths of this study is that physical therapists did have different background and work experience in years. Although physical therapists agreed on manual examination protocol and scale prior to the study, both of them did the evaluation based on their own experience and post graduate training on spinal mobility. The inter-rater reliability may have been different if the physical therapists had had similar experience and post graduate background in manual therapy. This should be evaluated in future studies whether the similar manual therapy training would improve the inter-rater reliability of manual mobility examination of thoracic spine. Finally, one strength of the current study is that we have reported wide range of reliability data such as ICC with 95\% confidence intervals, Cronbach's alpha, SEM, mean of differences, CR and Bland-Altman plots with their $95 \%$ limits of agreement and linear regression for proportional bias. Reporting the CR can help a clinician to evaluate clinically meaningful change in patients' as it quantifies the absolute reliability measurement error using the same units as the measurement device itself. CR is directly related to the $95 \%$ limits of agreement by Bland-Altman plots on same subject and it takes random and systematic errors into account. Thus, the change is real with 95\% confident in subjects' measurements, if it is higher than CR [34].

\section{Conclusion}

In subjects with thoracic spine pain, daily intra-rater reliability was strong or very strong for inspection of the posture and manual mobility evaluation methods mobility of the thoracic spine. Moreover, inter-rater reliability was strong or very strong for the evaluation of posture with inclinometer and flexion mobility using a tape measure. Both intra-rater and inter-rater reliability were lower in evaluating the thoracic spine mobility with inclinometer. 


\section{Supplementary information}

Supplementary information accompanies this paper at https://doi.org/10. 1186/s12891-020-03551-4.

Additional file 1. Additional Figure. 1-7. Bland-Altman plot for agreement of posture inspection in standing (1A and $1 B)$, posture inspection in sitting (2A and $2 \mathrm{~B}$ ), segmental mobility into flexion (3A and $3 B$ ), segmental mobility into extension (4A and $4 B$ ), posterior to anterior pressure $(5 A$ and $5 B)$, inclination of $71-6$ in standing (6A and $6 B)$, inclination of T6-12 in standing (7A and 7B), inclination of T1-12 in standing ( $8 \mathrm{~A}$ and $8 \mathrm{~B})$, inclination of $\mathrm{T} 1-6$ in sitting (9A and $9 \mathrm{~B})$, inclination of T6-12 in sitting (10A and 10B), inclination of T1-12 in sitting (11A and 11B), C7-T5 flexion mobility (12A and 12B), Schober in neutral (13A and 13B), Schober in flexion (14A and 14B), Schober in extension (15A and 15B), flexion mobility of the T1-6 in sitting (16A and 16B), flexion mobility of the T6-12 in sitting (17A and 17B), flexion mobility of the T1-12 in sitting (18A and 18B), extension mobility of the T1-6 in sitting (19A and 19B), extension mobility of the T6-12 in sitting (20A and 20B) and extension mobility of the T1-12 in sitting (21A and $21 \mathrm{~B}$ ) between raters $(\mathrm{A})$ and within rater $(\mathrm{B})$. The red lines depict the mean difference between raters and dotted green lines depict 95\% limits of agreement in the Bland-Altman plot.

\section{Abbreviations}

VAS: Visual analogue scale; ICC: Intra-class coefficiency; R-MDQ: Roland-Morris disability questionnaire; TSPD: Thoracic spine pain and disability; PA: Posterior-anterior; SEM: Standard error of measurement; SD: Standard deviation; CR: Coefficient of repeatability

\section{Acknowledgements}

We would like to thank the staff and owners of Fysioteekki for providing the facilities for this study free of charge. Special thanks to Jyrki Madetoja (JM) who voluntarily participated into the study as a second examiner/physical therapist.

\section{Authors' contributions}

JT, JY, TP and AH designed the study. JT collected and analysed the data. JT, JY and $\mathrm{AH}$ interpreted the data. JT, JY, TP and $\mathrm{AH}$ read and approved the final manuscript.

\section{Funding}

Finnish Association of Orthopaedic Manual Therapy and Finnish Association of Physiotherapists. The fundings were granted for the collection of the data.

\section{Availability of data and materials}

The datasets used and/or analysed during the current study are available from the corresponding author on reasonable request.

\section{Ethics approval and consent to participate}

The current study is nested study of the larger thoracic spine treatment study that had ethical committee approval from Ostrobothnia Hospital District (approval number 234/2009). All participants gave written informed consent prior to participation.

\section{Consent for publication}

Not applicable.

\section{Competing interests}

The authors declare that they have no conflicts of interest.

\section{Author details}

'Faculty of Sport and Health Sciences, University of Jyvaskyla, Jyväskylä, Finland. ${ }^{2}$ Medical Research Center Oulu, University of Oulu and Oulu University Hospital, Oulu, Finland. ${ }^{3}$ Central Finland Central Hospital, Jyväskylä, Finland. ${ }^{4}$ The Social Insurance Institution of Finland, Helsinki, Finland.
Received: 11 October 2019 Accepted: 31 July 2020

Published online: 10 August 2020

\section{References}

1. Briggs AM, Smith AJ, Straker LM, Bragge P. Thoracic spine pain in the general population: prevalence, incidence and associated factors in children, adolescents and adults. A systematic reviw. BMC Musculoskelet Disord. 2009;10:77.

2. Niemeläinen $\mathrm{R}$, Videman $\mathrm{T}$, Battie MC. Prevalence and characteristics of upper or mid-back pain in Finnish men. Spine. 2006;31:1846-9.

3. Briggs AM, Bragge P, Smith AJ, Govil D, Straker LM. Prevalence and associated factors fot thoracic spine pain in the adult working population. A literature review. J Occup Health. 2009:51:177-92.

4. Edmondston SJ, Singer KP. Thoracic spine: anatomical and biomechanical considerations for manual therapy. Man Ther. 1997:2:132-43.

5. Willems J, Jull G, Ng J. An in vivo study of the primary and coupled rotations of the thoracic spine. Clin Biomech. 1996/9;11:311-6.

6. Liebsch C, Graf N, Appelt K, Wilke HJ. The rib cage stabilizes the human thoracic spine: An in vitro study using stepwise reduction of rib cage structures. PLoS One. 2017:12(6):e0178733.

7. White AA III, Panjabi MM. Clinical biomechanics of the spine. 2 nd ed. Philadelphia: Lippincott Williams and Wilkins; 1990. p. 85-126.

8. Tsang SM, Szeto GP, Lee RY. Normal kinematics of the neck: the interplay between the cervical and thoracic spines. Man Ther. 2013;18:431-7.

9. Edmondston SJ, Ferguson A, Ippersiel P, Ronningen L, Sodeland S, Barclay L. Clinical and radiological investigation of thoracic spine extension motion during bilateral arm elevation. J Orthop Sports Phys Ther. 2012;42:861-9.

10. Wirth B, Amstalden M, Perk M, Boutellier U, Humphreys BK. Respiratory dysfunction in patients with chronic neck pain - influence of thoracic spine and chest mobility. Man Ther. 2014;19:440-4.

11. van Kleef M, Stolker RJ, Lataster A, Geurts J, Benzon HT, Mekhail N. Thoracic pain. Pain Practice. 2010;10:327-38

12. Conroy JL, Schneiders AG. The T4 syndrome. Man Ther. 2005;10:292-6.

13. Dwyer A, Aprill C, Bogduk N. Cervical zygapophyseal joint pain patterns. I: a study in normal volunteers. Spine (Phila Pa 1976). 1990;15:453-7.

14. DeFranca GG, Levine LJ. The T4 syndrome. J Manip Physiol Ther. 1995;18:34-7.

15. Manchikanti L, Singh V, Pampati V, Beyer CD, Damron KS. Evaluation of the prevalence of facet joint pain in chronic thoracic pain. Pain Phys. 2002;5: 354-9.

16. Dreyfuss P, Tibiletti C, Dreyer SJ. Thoracic zygapophyseal joint pain patterns. A study in normal volunteers. Spine. 1994;19:807-11.

17. Fukui S, Ohseto K, Shiotani M. Patterns of pain induced by distending the thoracic zygapophyseal joints. Reg Anesth. 1997;22:332-6.

18. Beynon AM, Hebert JJ, Walker BF. The interrater reliability of static palpation of the thoracic spine for eliciting tenderness and stiffness to test for a manipulable lesion. Chiropr Man Therap. 2018:4;26:49.

19. Huijbregts PA. Spinal motion palpation: a review of reliability studies. J Manual Manip Ther. 2002:10:24-39.

20. Haneline MT, Young M. A review of intraexaminer and interexaminer reliability of static spinal palpation: a literature synthesis. J Manip Physiol Ther. 2009;32:379-86.

21. Barrett E, McCreesh K, Lewis J. Reliability and validity of non-radiographic methods of thoracic kyphosis measurement: a systematic review. Man Ther. 2014;19:10-7.

22. Williams R, Binkley J, Bloch R, Goldsmith $\mathrm{CH}$, Minuk T. Reliability of the modified-modified Schober and double inclinometer methods for measuring lumbar flexion and extension. Phys Ther. 1993;73:33-44.

23. Heneghan NR, Gormley S, Hallam C, Rushton A. Management of thoracic spine pain and dysfunction: a survey of clinical practice in the UK. Musculoskelet Sci Pract. 2019;39:58-66.

24. Karas S, Schneiders A, Reid D, Talisa V. Factors affecting confidence and knowledge in spinal palpation among international manual physica therapists. J Manual Manip Ther. 2016;24:166-73.

25. Viikari-Juntura E, Takala EP, Alaranta H. Neck and shoulder pain and disability. Evaluation by repetitive gripping test. Scand J Rehabil Med. 1988; 20:167-73.

26. Magee DJ. Orthopedic physical assessment. 4th ed. Phladelphia: Saunders; 2002. p. 168, 437, 445-46, 454

27. Póvoa LC, Ferreira APA, Silva JG. Validation of palpatory methods for evaluating anatomical bone landmarks of cervical spine: a systematic review. J Manip Physiol Ther. 2015;38:302-10. 
28. Norlander S, Aste-Norlander U, Nordgren B, Sahlstedt B. A clinical method for measuring segmental flexion mobility in the cervico-thoracic spine and a model for classification. Scand J Rehabil Med. 1995;27:89-98.

29. Czaprowski D, Pawlowska P, Gebicka A, Sitarski D, Kotwicki T. Intra- and Interobserver repeatability of the assessment of Anteroposterior curvatures of the spine using Saunders digital inclinometer. Ortop Traumatol Rehabil. 2012;2:145-53

30. Kaltenborn FM. The spine. In: Basic evaluation and mobilization techniques 2nd ed. Oslo: Olaf Norlis Bokhandel; 1993. p. 215, 223, 227.

31. Hengeveld E, Banks. Maitland's Vertebral Manipulation: Management of Neuromusculoskeletal Disorders, vol. 1. Edinburgh: Churchill Livingstone: 2013. p. 202.

32. Walter SD, Eliasziw M, Donner A. Sample size and optimal designs for reliability studies. Stat Med. 1998;17:3101-10.

33. Evans J. Straightforward statistics for the behavioral sciences. Pacific Grove, CA: Brooks/Cole Publishing; 1996.

34. Vaz S, Falkmer T, Passmore AE, Parsons R, Andreou P. The case for using the repeatability coefficient when calculating test-retest reliability. PLoS One. 8(9):e73990.

35. Ng JK, Kippers V, Richardson CA, Parnianpour M. Range of motion and lordosis of the lumbar spine: reliability of measurement and normative values. Spine. 2001;26:53-60.

36. Tousignant M, Boucher N, Bourbonnais J, Gravelle T, Quesnel M, Brosseau L. Intratester and intertester reliability of the Cybex electronic digital inclinometer (EDI-320) for measurement of active neck flexion and extension in healthy subjects. Man Ther. 2001;6:235-41.

37. Griegel-Morris P, Larson K, Mueller-Klaus K, Oatis CA. Incidence of common postural abnormalities in the cervical, shoulder, and thoracic regions and their association with pain in two age groups of healthy subjects. Phys Ther. 1992;72:425-31.

38. Cleland JA, Childs JD, Fritz JM, Whitman JM. Interrater reliability of the history and physical examination in patients with mechanical neck pain. Arch Phys Med Rehabil. 2006;87:1388-95.

39. Gonella C, Paris SV, Kutner M. Reliability in evaluating passive intervertebral motion. Phys Ther. 1982;62:436-44.

40. van Trijffel E, Anderegg Q, Bossuyt PM, Lucas C. Inter-examiner reliability of passive assessment of intervertebral motion in the cervical and lumbar spine: a systematic review. Man Ther. 2005;10:256-69.

41. Hansen BE, Simonsen T, Leboeuf-Yde C. Motion palpation of the lumbar spine-a problem with the test or the tester? J Manip Physiol Ther. 2006/0; 29:208-12.

42. Christensen HW, Vach W, Vach K, Manniche C, Haghfelt T, Hartvigsen L, et al. Palpation of the upper thoracic spine: An observer reliability study. J Manip Physiol Ther. 2002/6;25:285-92

43. Brismée J, Gipson D, Ivie D, Lopez A, Moore M, Matthijs O, et al. Interrater reliability of a passive physiological intervertebral motion test in the midthoracic spine. J Manip Physiol Ther. 2006/6;29:368-73.

44. Potter L, McCarthy C, Oldham J. Intraexaminer reliability of identifying a dysfunctional segment in the thoracic and lumbar spine. J Manip Physiol Ther, 2006/0. 29:203-7.

45. Robinson R, Robinson HS, Bjorke G, Kvale A. Reliability and validity of palpation technique for identifying the spinous processes of C7 and L5. Man Ther. 2009;14:409-14.

46. Heiderscheit B, Boissonnault W. Reliability of joint mobility and pain assessment of the thoracic spine and rib cage in asymptomatic individuals. J Manual Manip Ther. 2008;16:210-6.

47. Walker BF, Koppenhaver SL, Stomski NJ, Hebert JJ. Interrater reliability of motion palpation in the thoracic spine. Evid Based Complement Alternat Med. 2015:2015:815407.

48. Haas M, Panzer D, Peterson D, Raphael R. Short-term responsiveness of manual thoracic end-play assessment to spinal manipulation: a randomized controlled trial of construct validity. J Manip Physiol Ther. 1995;18:582-9.

49. Gavin D. The effect of joint manipulation techniques on active range of motion in the mid-thoracic spine of asymptomatic subjects. J Manual Manip Ther. 1999;7:114-22

50. Schiller $L$. Effectiveness of spinal manipulative therapy in the treatment of mechanical thoracic spine pain: A pilot randomized clinical trial. J Manip Physiol Ther. 2001/7;24:394-401.

51. Sung YB, Lee $J H$, Park YH. Effects of thoracic mobilization and manipulation on function and mental state in chronic lower back pain. J Phys Ther Sci. 2014;26:1711-4.
52. Hole DE, Cook JM, Bolton JE. Reliability and concurrent validity of two instruments for measuring cervical range of motion: effects of age and gender. Man Ther. 1995;1:36-42.

53. Portek I, Pearcy MJ, Reader GP, Mowat AG. Correlation between radiographic and clinical measurement of lumbar spine movement. $\mathrm{Br}$ J Rheumatol. 1983;22:197-205.

54. Rondinelli R, Murphy J, Esler A, Marciano T, Cholmakjian C. Estimation of normal lumbar flexion with surface inclinometry - a comparison of three methods. Am J Phys Med Rehab. 1992;71:219-24.

55. Post RB, Leferink VJM. Spinal mobility: sagittal range of motion measured with the SpinalMouse, a new non-invasive device. Arch Orthop Trauma Surg. 2004;124:187-92.

56. Mannion AF, Knecht K, Balaban G, Dvorak J, Grob D. A new skin-surface device for measuring the curvature and global and segmental ranges of motion of the spine: reliability of measurements and comparison with data reviewed from the literature. Eur Spine J. 2004;13:122-36.

57. Alricsson M, Björklund $\mathrm{G}$, Cronholm M, Olsson O, Viklund P, Svantesson U. Spinal alignment, mobility of the hip and thoracic spine and prevalence of low back pain in young elite cross-country skiers. J Exerc Rehab. 2018;12:21-8.

\section{Publisher's Note}

Springer Nature remains neutral with regard to jurisdictional claims in published maps and institutional affiliations.
Ready to submit your research? Choose BMC and benefit from:

- fast, convenient online submission

- thorough peer review by experienced researchers in your field

- rapid publication on acceptance

- support for research data, including large and complex data types

- gold Open Access which fosters wider collaboration and increased citations

- maximum visibility for your research: over $100 \mathrm{M}$ website views per year

At BMC, research is always in progress.

Learn more biomedcentral.com/submissions 